\title{
Analysis of the Protection Performance of Face Guard for Large Mining Height Hydraulic Support
}

\author{
Lirong Wan $\mathbb{D},{ }^{1}$ Shuai Zhang $\mathbb{D},{ }^{1}$ Zhaosheng Meng $\mathbb{D}^{2},{ }^{2}$ and Yunyue Xie $\mathbb{D}^{3}$ \\ ${ }^{1}$ College of Mechanical and Electronic Engineering, Shandong University of Science and Technology, Qingdao 266590, China \\ ${ }^{2}$ State Key Laboratory of Mining Disaster Prevention and Control Cofounded by Shandong Province \\ and the Ministry of Science and Technology, Shandong University of Science and Technology, Qingdao 266590, China \\ ${ }^{3}$ College of Civil Engineering and Architecture, Qingdao 266590, China
}

Correspondence should be addressed to Yunyue Xie; xieyunyue1991@163.com

Received 28 October 2020; Revised 25 December 2020; Accepted 2 March 2021; Published 12 March 2021

Academic Editor: Francesco Marulo

Copyright (c) 2021 Lirong Wan et al. This is an open access article distributed under the Creative Commons Attribution License, which permits unrestricted use, distribution, and reproduction in any medium, provided the original work is properly cited.

\begin{abstract}
With the increase of mining height, the problem of coal wall spalling in the working face gradually worsens. Hydraulic support and its face guard structure are the key pieces of equipment to restrain the coal wall spalling. However, at present, the hydraulic jack is mostly considered as rigid in the analysis of protection mechanism. This simplification cannot effectively reflect the true bearing state of the face guard. In order to improve the accuracy of analysis, this study considers the face guard jack as a flexible spring and establishes a rigid-flexible coupling analysis model of the face guard mechanism. First, based upon the multibody dynamics software ADAMS ${ }^{\circledR}$, the multibody numerical model of the face guard of the hydraulic support was established. The influence of the two kinds of structures on the coal wall disturbance was analyzed and compared. Then, the rigid model was meshed. The hydraulic jacks were equivalent to the spring system, and the rigid-flexible coupling model was established. Based upon the application load on different positions of the rigid-flexible model, the loadbearing characteristics and hinge point force transfer characteristics of the two face guards were analyzed. The results show that the support efficiency of the integral type was higher than that of the split type. In the vertical support attitude, the dynamic disturbance of the coal wall, produced by the two kinds of face guards, was small. The four-bar linkage effectively improved the ultimate bearing capacity of the integral face guard. The results provide theoretical support for the design and optimization of the face guard.
\end{abstract}

\section{Introduction}

Although, in recent years, coal mining and coal consumption have gradually decreased with the increase in support towards reducing carbonization, the total global coal production has still increased by $1.5 \%$ in 2019 compared with that in the previous year. China, as a country with more coal and less oil and gas, accounts for $51.7 \%$ of the global coal consumption. In a long period of time, coal will still be an irreplaceable key primary energy resource in China. There are a large number of thick coal seams in Western China. At present, there are two main mining methods for thick coal seams, namely, the large mining height one-time fullthickness mining and sublevel caving mining $[1,2]$. In recent years, with the continuous development of mining technology, the coupling support theory of large mining height hydraulic support and surrounding rock has gradually improved $[3,4]$. However, due to the continuous increase in mining height, the probability and extent of damage of the overlying strata in the working face has increased rapidly, which has led to severe roof impact load phenomenon and the rapid deterioration of the coal wall stress level. Therefore, during mining with large mining height, large-scale and deep spalling can still occur [5-7]. In addition, the coal wall 
spalling phenomenon also aggravates the instability of the hydraulic support in the working face (two legs hydraulic support) [8]. Therefore, the problem of spalling is still a key challenge restricting the mining of thick coal seams.

As the problem of spalling has a great impact on the production of coal, many scholars around the world have studied the problem of coal wall spalling. First, the stability factors of the surrounding rock were analyzed using indoor experiments and theoretical analysis as reported in some previous studies $[9,10]$. Moreover, based on the Hoek-Brown failure criterion, a prediction model of the mechanical parameters of the surrounding rock was established. In the study of the mechanism of coal wall spalling, some previous works [11-14] have studied the influence of mining height, roof pressure, and other factors on the scope and depth of coal wall spalling. It is considered that, with the increase of mining height and roof pressure, the probability of coal wall spalling in the working face also increases. Based on the "wedge" stability theory, some previous works $[15,16]$ studied the mechanism of coal wall spalling in fully mechanized mining face with large mining height. In addition, they pointed out that the physical properties of coal body, the face guard protection force of hydraulic support, and the protection efficiency affected the stability of coal wall. In a previous work [17], the numerical model of 8102 working face in the Wolonghu mine (China) was established with the help of UDEC. Furthermore, the influence of the coal seam dip angle on the stability of coal wall was analyzed, and it was pointed out that the fracture mode of coal wall changed with the change of coal seam dip angle (tensile or shear fractures). In another work [18], based on the systematic analysis of the factors affecting the stability of coal and rock in large mining height working face, the triangular slope spalling caused by shear slip was found to be the main failure mode of coal wall spalling with large mining height. By establishing the interaction model of hydraulic support and surrounding rock under different roof structures, a previous study [19] analyzed the influencing factors of hydraulic support stability in fully mechanized mining face. The results showed that coal wall spalling would worsen the bearing condition of support, while the degree of spalling was negatively correlated with the support strength required by the hydraulic support. From the perspective of hydraulic support, the structural characteristics of hydraulic support were studied [20] by establishing the corresponding three-dimensional (3D) model, and numerical simulation analysis was also carried out. The results showed that the mechanical structure of the hydraulic support had a certain impact on the support. Some previous works [21-24] established the stope analysis model of fully mechanized mining face using theoretical calculations and finite element software FLAC 3D. The working resistance and support force of the face guard were made equivalent to static rigid force by changing the working resistance and the horizontal support force of the face guard. The restraining effect of the active support force of the face guard on the coal wall spalling was analyzed. The results showed that the support resistance and the support force of the face guard were the two important factors restraining the coal wall spalling, which were taken as the criteria for selecting the reasonable working resistance of the hydraulic support. In order to simulate and analyze the influence of hydraulic support and surrounding rock in various coupling states on the bearing characteristics of hydraulic support face guard and other components [25-27], different coupling states were simulated by changing the size and position of applied external load. It was found that the change of coupling state would cause damage to the hydraulic support components. Among them, the face guard mechanism is of great significance to maintaining the stability of coal wall. However, there is little research on the mechanism of the support. The available references assume that the face guard is a rigid body and that the face guard and the coal wall are in an ideal coupling state. In practice, due to the unevenness of the coal wall cut by the shearer, there are many forms of contact states between the face guard and the coal wall in actual work. Meanwhile, the face guard is close to the coal wall, which also forms a dynamic disturbance force for the coal wall. Based on these reasons, this study analyzes the performance of high mining height hydraulic support from two aspects, namely, the dynamic disturbance of the coal wall caused by the action of the face guard and the bearing characteristics of the face guard. The multibody numerical model of the face guard of the support is established using the multibody dynamics software ADAMS, and the influence of the action of the two kinds of structures on the dynamic disturbance of the coal wall is analyzed. The two types of structures are the integral face guard and the split face guard. Based upon the flexible replacement of each structural part of the face guard, the bearing characteristics and the force transmission characteristics of the two kinds of face guards under different coupling states of the face guards and the coal wall are analyzed and compared.

The current study is arranged as follows. In the second section, the dynamic disturbance of the coal wall caused by the action of the two kinds of structures is analyzed. In the third section, the rigid-flexible coupling numerical analysis model is established, and the ultimate bearing capacity of the two kinds of face guards is analyzed. The fourth section compares and analyzes the load-bearing characteristics of the face guard mechanism under different coupling states between the face guard and the coal wall. Section 5 summarizes the conclusions.

\section{Analysis of the Dynamic Disturbance of Coal Wall by Face Guard}

2.1. Analysis of the Working Principle of the Face Guard. Through direct contact with the coal wall, as shown in Figure 1, the face guard of hydraulic support exerts support force on the free surface of the coal wall. This can effectively delay the coal body damage and prevent the coal wall falling. This can also prevent the ejection injury of coal wall, which can cause structural damage.

At present, there are two kinds of structures of the hydraulic support face guard that are suitable for large mining height working face, as shown in Figure 2. In one of the structures, the face guard of the hydraulic support is 


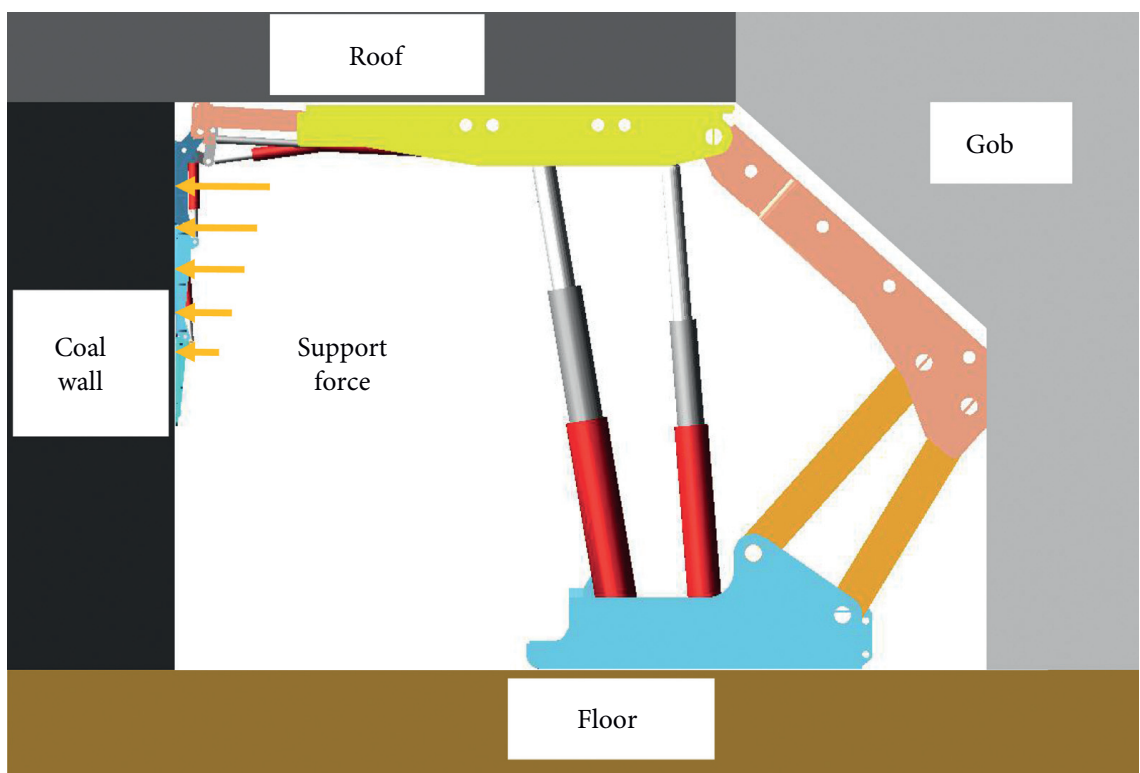

FIGURE 1: Schematic of the coal wall supported by the hydraulic support.

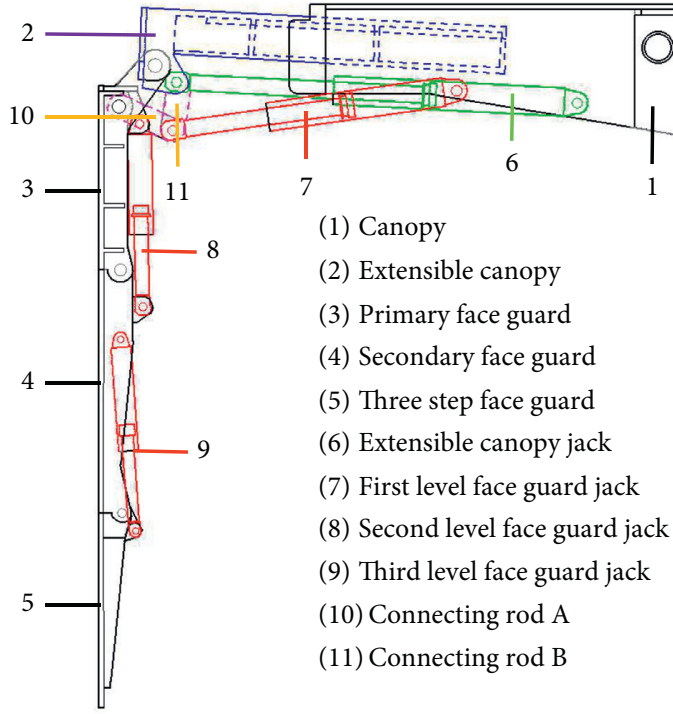

(a)

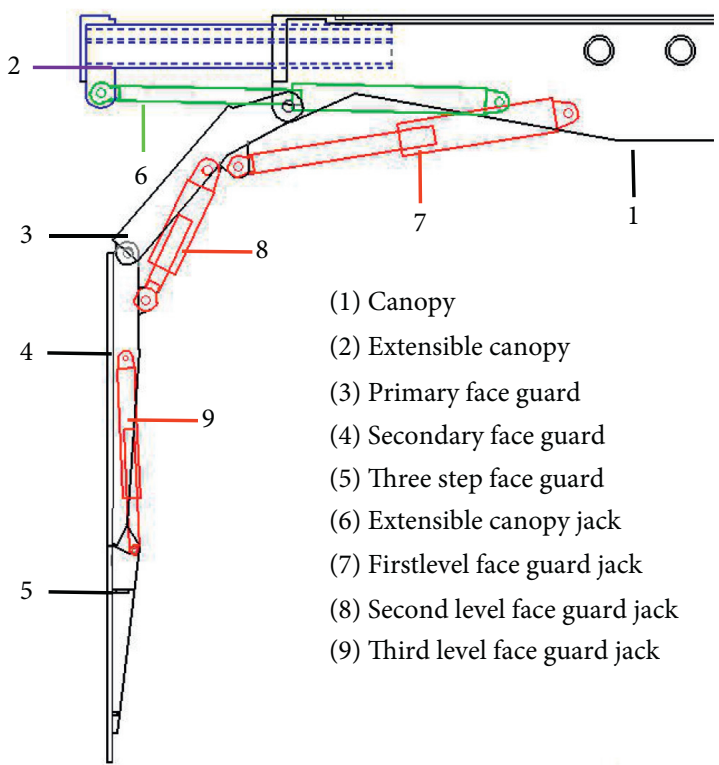

(b)

Figure 2: Comparison of the two kinds of hydraulic support face guard mechanisms. (a) Integral face guard. (b) Split face guard.

directly hinged with the front part of the extensible canopy. When the extensible canopy is extended, the face guard will also extend. The setup is called the integrated face guard structure. In the second kind of hydraulic support, the extensible canopy and face guard are separate structures. The face guard is installed at the front of the canopy, which means that the extensible canopy can move independently, and is called the split face guard structure. The function and composition of the two kinds of face guards are basically the same. However, for the hydraulic support with integral face guard structure, the primary face guard and the extensible canopy are usually connected through four-bar linkage, and the split type face guard structure is connected using the simple hinge joint of the primary face guard and the canopy.

2.2. Disturbance Analysis of the Coal Wall Caused by the Action of Face Guard. After the shearer cuts coal, the coal wall has to bear the vertical pressure of the overlying roof and the horizontal force of the front coal body. Under this scenario, the stress situation becomes complex. The face guard of hydraulic support applies a horizontal force to the coal wall, which can effectively prevent the coal body from spalling and change the stress situation of coal wall. 
Therefore, after coal cutting, the face guard needs to support the coal wall in time [28]. Whether the hydraulic support face guard can fit the coal wall timely and effectively or not has an important influence on the coal wall protection. Therefore, the efficacy of the action of the hydraulic support face guard from the retracted position to the expected designated position is an important index for evaluating the performance of the face guard.

At the same time, it has been reported that this kind of plate cracking phenomenon exists in coal wall and roadways $[29,30]$. However, when the coal wall of the working face is cracked, the support action will cause dynamic disturbance to the plate cracking area of coal wall, which will lead to the occurrence of plate cracking spalling disaster. Therefore, the dynamic disturbance characteristic of the face guard is another index to evaluate its performance. In this study, a large mining height hydraulic support ZZ 18000/33/72D adopted in Jinjitan coal mine (China) was taken as the example. This was performed due to the reason that longitudinal crack failure occurred during the periodic weighting period. The face protecting action of the support also aggravates the plate cracking and spalling of coal wall, as shown in Figure 3.

During the process ranging from the opening of the primary and secondary face guards to the large area fitting with the coal wall, during the contact process between the two kinds of structures and the coal wall, it is usual that the secondary face guard first comes into contact with the coal wall. When it contacts the coal wall, the face guard has a certain speed and gradually changes into surface contact with the movement of the face guard jack. Thus, the opening process of the face guard will cause dynamic disturbance to the coal wall, which is not conducive to the stability of the coal wall. As shown in Figure 4, when the coal wall has been damaged by the tension caused by the mine pressure and the longitudinal or transverse through-cracks are generated, the impact of the face guard on the coal wall is likely to cutoff the coal wall and cause local spalling. Therefore, by testing the angular velocity of the face guard during the process of opening, the dynamic disturbance effect of the face guard on the coal wall can be analyzed.

In order to compare the integral face guard and the split face guard, the time required for the face guard to reach the expected supporting state is determined, and the dynamic disturbance to the coal wall is analyzed. Based on ADAMS software, the multibody dynamic analysis model of the face guard mechanism of the hydraulic support is established, as shown in Figure 5. Each structural member is treated as a rigid body. Various components, such as the extensible canopy, the face guard, and the face guard jack, are defined as the rotating pair connection. The first level of the face guard jack is defined as the moving pair connection. Additionally, the other levels of the face guard are defined as the fixed connection; therefore, it can move along with the primary face guard and be relatively static. The moving pair of the first level face guard jack is driven, and the extension speed of the first level face guard jack of the two types of structures is controlled to be $90 \mathrm{~mm} / \mathrm{s}$. Furthermore, the frictional coefficient is set to be 0.3 . Meanwhile, the canopy,

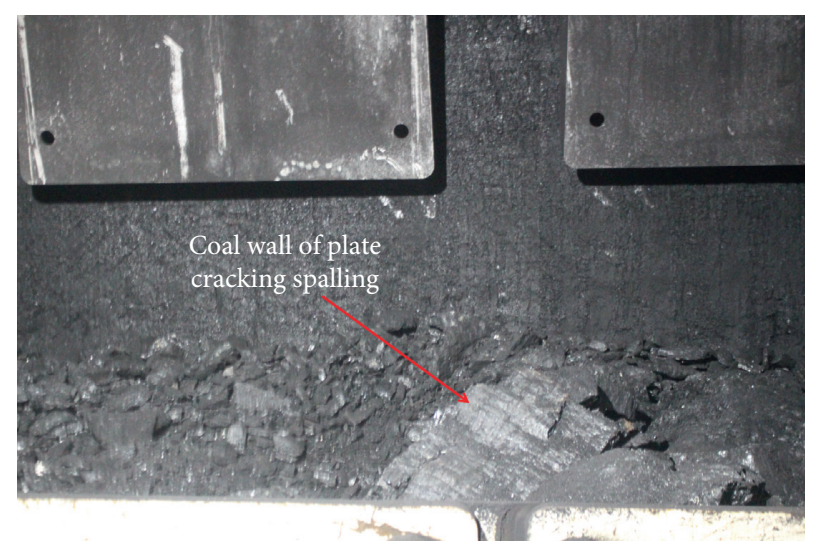

FIgURE 3: Plate cracking phenomenon in Jinjitan coal mine, China.

goaf shield, and other parts are fixed and connected with the ground to keep them still. The same jack is used for the two structural forms of the face guards. Specific parameters of the face guard jack for various levels are presented in Table 1.

The performance results of the two kinds of face guards are shown in Figure 6. The measurement of the two kinds of face guard starts when the horizontal angle with the top beam is $10^{\circ}$. Under the condition of same and constant extension speed of the face guard jack, it takes $6.4 \mathrm{~s}$ for the integral face guard to open to $140^{\circ}$ and $8.9 \mathrm{~s}$ for the split face guard. It can be inferred that when the two kinds of face guards are close to the vertical coal wall, the angular velocity decreases to the lowest value. The minimum value of the angular velocity remains basically the same. However, the action speed of the integral face guard becomes faster. Therefore, under the condition of a small influence on coal wall disturbance, the integral face guard can realize the support of coal wall more quickly. Meanwhile, based upon the measurements and statistics of the angular velocity of the two kinds of structures during opening, it can be found that the angular velocity of the face guard decreases at first and then increases. On the other hand, the minimum value of the angular velocity exhibits a small difference. When the angular velocity of the integral and split face guards is the minimum, the corresponding opening angles are $87^{\circ}$ and $94^{\circ}$, respectively. This means that the dynamic disturbance of the face guard to the coal wall can be minimized. Therefore, during the opening process of the two kinds of structures, the extensible canopy jack and the face guard jack should be controlled cooperatively to make it fit with the coal wall for the opening angle of $\mathrm{ca} 90^{\circ}$. This is performed to minimize the dynamic disturbance of the coal wall by the face guard, reduce the impact force on the coal wall, and avoid the local spalling of the coal wall caused by the face guard cutting off the coal wall. However, when the coal wall is convex or concave into a part of the angle, the split face guard has fewer disturbances to the coal wall because the angular velocity changes more smoothly. This means that it shows better adaptability.

\section{Analysis of the Bearing Capacity of the Face Guard}

During the advancement of working face, the hydraulic support face guard exerts active support force on the coal 


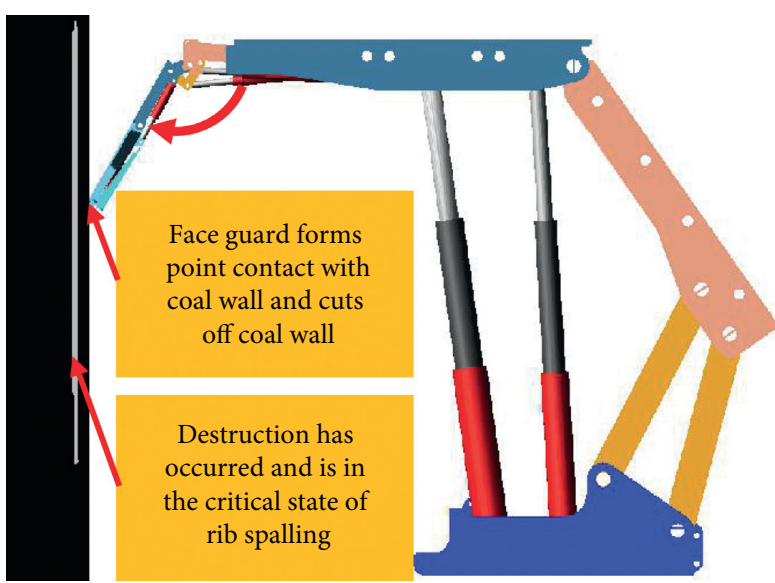

(a)

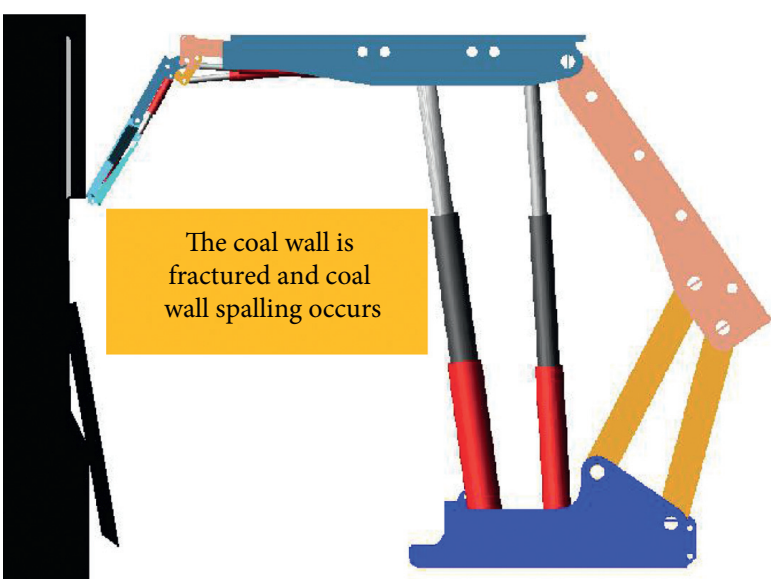

(b)

Figure 4: Schematic of the coal wall cutting by face guard.

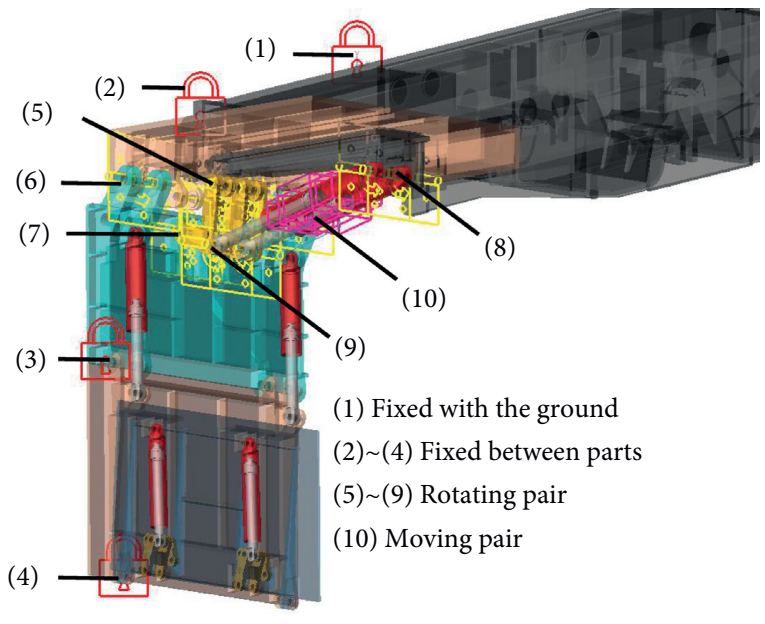

(a)

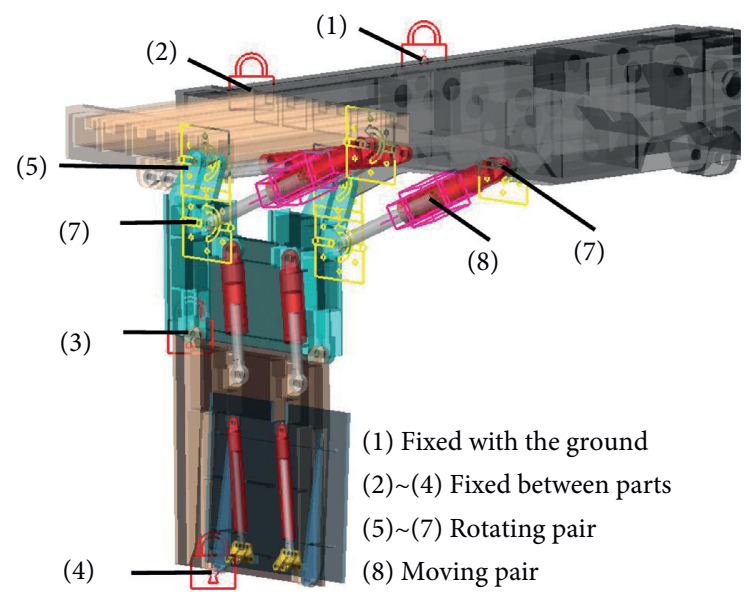

(b)

Figure 5: Dynamic analysis model of the face guard. (a) Integral face guard. (b) Split face guard.

TABle 1: Parameters of the face guard jack.

\begin{tabular}{lccc}
\hline & Cylinder diameter/mm & Piston diameter/mm & Working resistance/KN \\
\hline First level & 125 & 90 & 490 \\
Second level & 100 & 70 & 300 \\
Third level & 80 & 60 & 190 \\
\hline
\end{tabular}

wall by being close to the coal wall to prevent the coal wall from spalling. Meanwhile, the coal wall will also form a reaction force of the same size and of opposite direction on the face guard. The ultimate bearing capacity of the face guard is analyzed by applying external load on the face guard, and the support capacities of different structural forms of the face guards are compared. Due to the different degrees of damage and flatness of coal wall in the process of coal mining machine advancing, the face guard and coal wall are not in the ideal state of complete fit in the working face. Instead, they are mostly in the single point support state. Therefore, the force of coal wall on the face guard is simplified as the point load. On the other hand, the ultimate bearing capacity of the face guard at different positions is obtained by applying the point load to different positions of the face guard. Since the force of the three-step face guard is small and the stress situation is similar to that of the primary and secondary face guards, only the primary and secondary face guards of the two structural forms are analyzed.

3.1. Theoretical Analysis of the Bearing Capacity of the Integral Face Guard. The stress analysis of the integral face guard is shown in Figure 7. The hinge joint of the extensible canopy 


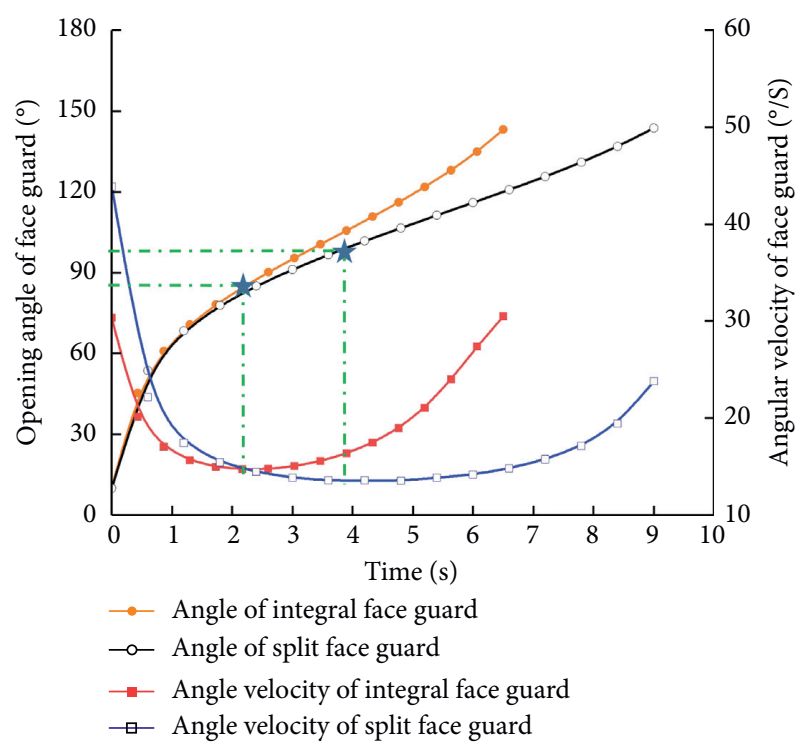

FIgURE 6: Comparison of the motion characteristics between the two kinds of face guards.

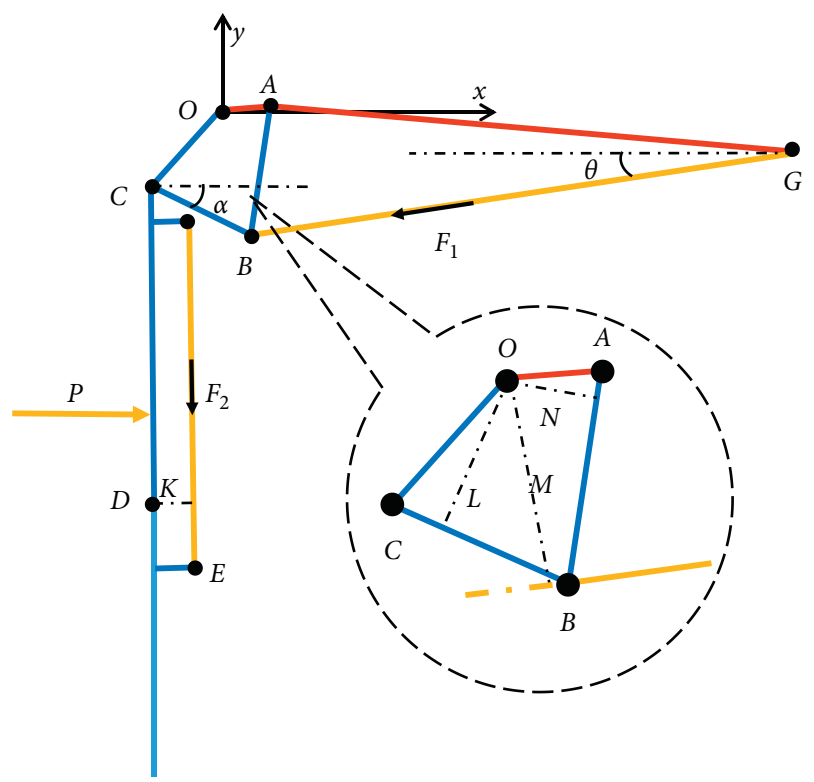

FiguRE 7: Stress analysis diagram of the integral face guard.

and the primary face guard are taken as the origin $O$. Moreover, $\mathrm{OA}, \mathrm{OC}, \mathrm{AB}$, and $\mathrm{BC}$ constitute a four-bar linkage. Furthermore, $F_{1}$ is the force of the first level face guard jack on the hinge point $B$, while $F_{2}$ is the force of the second level face guard jack on the hinge point $E$. Additionally, $F_{i j}$ is the force of point $i$ on point $j$ (for example, $F_{\mathrm{BC}}$ is the force of point $B$ on point $C$ ). The distance from point $O$ to rod $B C$ is $L$. In addition, the distance from point $O$ to rod $\mathrm{AB}$ is $M$. Similarly, the distance from point $O$ to $F_{1}$ extension line is $N$, and the distance from point $O$ to $F_{2}$ is $K$. Moreover, $y_{P}$ is the vertical distance from external load $P$ to corresponding hinge point $O$. The angle between the acting force of the first level face guard jack and the horizontal direction is $\theta$, and the angle between the rod $\mathrm{BC}$ and the horizontal direction is $\alpha$.

At this time, the mathematical model of the ultimate bearing capacity of the integral face guard can be established.

When the loading position of the external load $P$ is at the primary face guard, the forces are given by the set of following equation.

$$
\left\{\begin{array}{l}
F_{1} \cdot \cos \theta-F_{B C} \cdot \cos \alpha=0, \\
F_{1} \cdot \sin \theta-F_{B C} \cdot \sin \alpha=0, \\
F_{A B} \cdot M=F_{B C} \cdot L, \\
F_{A B} \cdot M=F_{1} \cdot N, \\
F_{B C} \cdot L=P \cdot y_{P} .
\end{array}\right.
$$

It is necessary to calculate the value $P_{1}$ according to equation (1) when the loading position of the external load is at the primary face guard. When the external load $P$ is in the secondary face guard, the ultimate bearing capacity of the second level face guard jack must be considered. This is due to the reason that the first level and second level face guard jacks are simultaneously under pressure. In this case, it is necessary to add the following equation to the model.

$$
\begin{cases}P=P_{1}, & P_{1} \cdot\left(y_{D}-y_{P}\right)-F_{2} \cdot K \leq 0, \\ P \cdot\left(y_{D}-y_{P}\right)=F_{2} \cdot K, & P_{1} \cdot\left(y_{D}-y_{P}\right)-F_{2} \cdot K>0 .\end{cases}
$$

According to the model size parameters, $M=136.43 \mathrm{~mm}$ and $N=342.4 \mathrm{~mm}$, while $K=111.95 \mathrm{~mm}$. The loading position of the external load $P$ determines that $100 \mathrm{~mm}<y_{P}<2100 \mathrm{~mm}$, whereas $y_{D}=-1049.75 \mathrm{~mm}$, including the angle $\alpha=24^{\circ}$. The maximum tension and compression working resistance of the first level face guard jack are $490 / 264 \mathrm{kN}$. Furthermore, the maximum pressure working resistance of the second level face guard jack is $300 \mathrm{kN}$. Therefore, the maximum load-bearing capacity of the primary face guard under compression is $980 \mathrm{kN}$. The maximum bearing capacity under tension is $-528 \mathrm{kN}$. Furthermore, the maximum bearing capacity of the secondary face guard is $600 \mathrm{kN}$ under compression. Moreover, the maximum working resistance of the extensible canopy jack is always greater than its bearing capacity. According to the above parameters, the bearing capacity of the integral face guard is analyzed and calculated, and the corresponding results are shown in Figure 8.

3.2. Theoretical Analysis of the Bearing Capacity of the Split Face Guard. The stress analysis of the split face guard structure is shown in Figure 9. Because the primary face guard is connected with the canopy through a simple hinge joint, the stress analysis is relatively simple, and the external load can be obtained using equations (3) and (4). The hinge joint of the primary face guard and the canopy is taken as the coordinate origin $O$, and the coordinate system is established. The force on point $D$ of the first level face guard jack is $F_{1}$, whereas $F_{2}$ is the force of the second level face guard jack to point $B$. In this structure, the primary face guard does not 


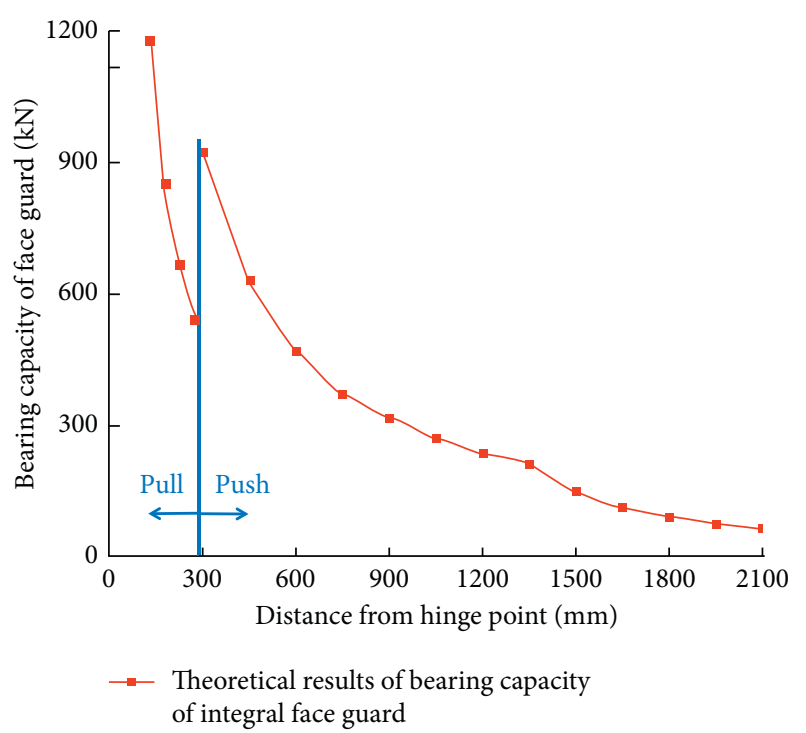

FIgURE 8: Theoretical value of bearing capacity of the integral face guard.

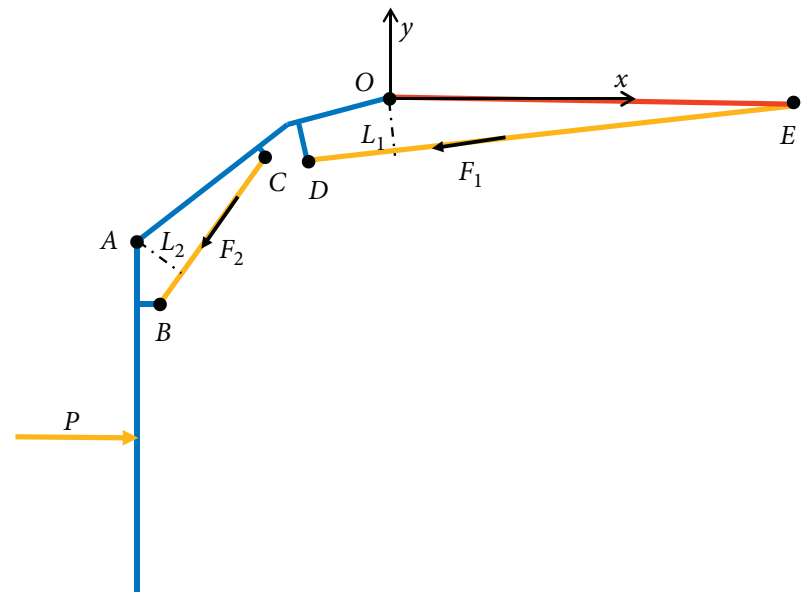

Figure 9: Stress analysis diagram of the split face guard.

contact the coal wall, and only the external load is applied at the secondary face guard. However, it is also necessary to consider the maximum working resistance of the first level and second level face guard jacks.

When the loading position of the external load is in the secondary face guard, only the first level face guard jack is considered (equation (3)).

$$
F_{1} \cdot L_{1}=P_{1} \cdot y_{P}
$$

Considering the second level face guard jack, the following equation is added to the model.

$$
\begin{cases}P=P_{1}, & P_{1} \cdot\left(y_{A}-y_{P}\right)-F_{2} \cdot L_{2} \leq 0, \\ P \cdot\left(y_{A}-y_{P}\right)=F_{2} \cdot L_{2}, & P_{1} \cdot\left(y_{A}-y_{P}\right)-F_{2} \cdot L_{2}>0 .\end{cases}
$$

According to the model parameters of the split type face guard, $L_{1}=229.65 \mathrm{~mm}, L_{2}=239.95 \mathrm{~mm}, y_{A}=-615.03 \mathrm{~mm}$, and $800 \mathrm{~mm}<y_{P}<2100 \mathrm{~mm}$. In order to ensure that there are only structural differences between the two types of face guards, the uniqueness of the control variables, all the other variables are the same except for the different structures of the face guards. Two jacks with the maximum working resistance of $490 \mathrm{kN}$ are used for the primary face guard, while two jacks with the maximum working resistance of $300 \mathrm{kN}$ are used for the analysis of the secondary face guard. Therefore, $F_{1}=980 \mathrm{kN}$ and $F_{2}=600 \mathrm{kN}$. The corresponding results are shown in Figure 10.

3.3. Numerical Model of the Face Guard Mechanism of the Hydraulic Support. Based upon the HyperMesh software, the three-dimensional (3D) models of the two kinds of hydraulic supports are imported into Adams in the form of mnf file [31-33]. The canopy and the goaf shield of the hydraulic support are all defined as rigid bodies. The friction rotary pair is used to connect the extensible canopy and the face guard and for connecting the rod and the face guard. Similarly, they are also used to connect the rod and the extensible canopy and the two connecting rods. The frictional coefficient is set to be 0.3 , while the face guard jack is replaced by an equivalent spring. At the same time, the canopy, goaf shield, and other rigid body parts are fixed, connected with the ground. The numerical simulation models of the two kinds of face guards are shown in Figure 11.

According to the calculation of the equivalent spring stiffness of jack, the equivalent spring stiffness of jack under different working conditions can be obtained (equation (5)).

$$
K=\frac{A \cdot \gamma}{L}
$$

where $K$ is the equivalent stiffness coefficient $(\mathrm{N} / \mathrm{m}), A$ is the effective area of the hydraulic cylinder when transmitting liquid pressure $\left(\mathrm{m}^{2}\right), \gamma$ is the bulk elastic modulus of the hydraulic fluid (oil in water emulsion) having a value of $1.95 \times 10^{3} \mathrm{MPa}$, and $L$ is the length of the effective liquid column in the hydraulic cylinder $(m)$. In this model, the opening angle of the face guard is the same as that of the theoretical analysis model, which is $90^{\circ}$. After measuring the position parameters of the first and second level face guard jacks, it is determined that when the jack of the first level face guard is under pressure, the equivalent spring stiffness coefficient is $5.5 \times 10^{7} \mathrm{~N} / \mathrm{m}$. However, when the jack of the first level face guard is pulled, the equivalent spring stiffness coefficient becomes $3 \times 10^{7} \mathrm{~N} / \mathrm{m}$. The equivalent spring stiffness coefficient of the second face guard jack is $6.1 \times 10^{8} \mathrm{~N} / \mathrm{m}$. The same spring stiffness coefficient is set for the two kinds of face guards.

3.4. Numerical Analysis and Comparison. Based on the above numerical model, on the vertical centerline of the integral primary and secondary face guards and the split-type secondary face guard, different loads are applied on the points with an interval of $260 \mathrm{~mm}$. Then, the bearing capacities of the two kinds of face guards are simulated and analyzed. The load amplitude is estimated using the above theoretical 


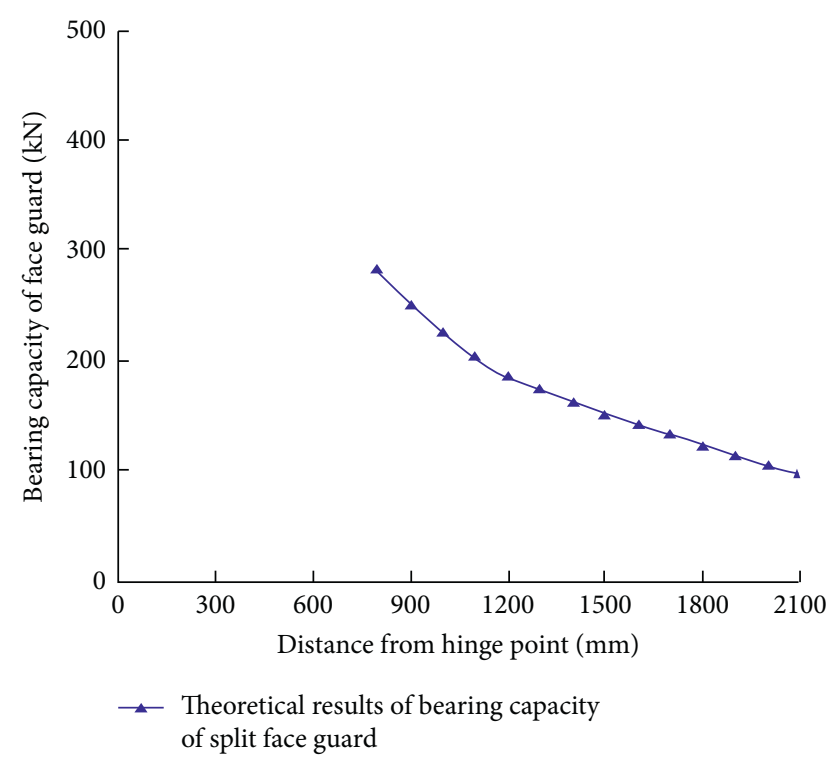

FIgURE 10: Theoretical value of the bearing capacity of the split face guard.

analysis results and corrected according to the response of the face guard jack (the ultimate bearing capacity of the face guard is taken as the loading force of the critical overflow of the face guard jack).

The comparison of the numerical and theoretical results is shown in Figure 12. It can be seen that the error between the numerical and theoretical results is less than $2.3 \%$, which indicates good consistency. The results of theoretical calculation and numerical simulation are compared and analyzed. Based upon the comparison and analysis, following conclusions can be drawn. When the loading position of the integral face guard is less than $1500 \mathrm{~mm}$ from the hinge joint, the maximum bearing capacity can reach $900 \mathrm{kN}$. Compared with the split face guard, it has obvious advantages. When it is more than $1500 \mathrm{~mm}$ away from the hinge joint, the bearing capacity of the integral face guard is slightly lower than that of the split face guard, though the difference is small. Both of them are between $70 \mathrm{kN}$ and $150 \mathrm{kN}$. Besides, due to the structural differences, the split-type primary face guard cannot directly contact the coal wall. This results in a less effective support area as compared with the integral face guard. Therefore, the bearing capacity and bearing range of the integral face guard are better than those of the split face guard.

\section{Performance Analysis of the Face Guard under Different Coupling States}

4.1. Analysis of the Load-Bearing Capacity of the Face Guard under Different Coupling States. There are many coupling states between the face guard and the coal wall of the hydraulic support. For example, due to the uneven coal wall, only one side of the face guard can contact the coal wall. The other side has no contact. In this case, the loading position of the external load is simply regarded as on the centerline of the face guard. It does not conform to the actual situation.
Therefore, based on the above numerical model, the load is applied at different positions of the face guard to analyze the bearing capacity under different coupling states. As shown in Figure 13, considering the integral face guard as an example, the centerline of the circular hole at the hinge joint of the primary face guard and the extensible canopy is taken as the $X$-axis (in the split face guard, the centerline of the round hole at the hinge joint of the face guard and the canopy is taken as the $X$-axis). Moreover, the centerline perpendicular to the $X$ axis is taken as the $Y$-axis of the two kinds of face guards. A cushion block is set at each interval of $\Delta L=165 \mathrm{~mm}$ in the $X$ axis direction. Furthermore, a cushion block is arranged for every $\Delta M=154 \mathrm{~mm}$ in the $Y$-axis direction. In order to facilitate the comparative analysis between the integral and split-type face guards, the integral first level face guard jack only considers the compression state. Therefore, the cushion block position is $y_{P}>300 \mathrm{~mm}$. The cushion blocks are arranged in this way for the integral primary and secondary face guards and the split secondary face guard to simulate different coupling modes of the coal wall and the face guard.

The bearing capacity of the integral face guard and split face guard is shown in Figure 14. According to the numerical results, the maximum bearing capacity of the integral face guard is $900 \mathrm{kN}$, while the minimum bearing capacity is $47 \mathrm{kN}$. The maximum bearing capacity of the split face guard is $276 \mathrm{kN}$. On the other hand, the minimum value is $82 \mathrm{kN}$. At the same time, it is not difficult to see that the bearing capacity of the integral and split face guards has the same variation trend. When the loading position is close to the $O$ point position, the bearing capacity of the face guard has an obvious increasing trend compared with the other positions. When the position of the $Y$-axis is the same and $X=0$ (the centerline position of the face guard), the bearing capacity is the largest. Interestingly, the bearing capacity is symmetrical on the left and right sides of the $X$-axis. When the $X$-axis position is the same, the $Y$-axis coordinate value is inversely proportional to the bearing capacity of the face guard.

In order to more intuitively compare the bearing capacities of the two kinds of face guards in different coupling states, four rows of cushion blocks corresponding to the integral and split face guards are taken for analysis. The coordinates of the four lines are given by $X_{1}=280 \mathrm{~mm}$, $X_{2}=560 \mathrm{~mm}, Y_{1}=840 \mathrm{~mm}$, and $Y_{2}=1300 \mathrm{~mm}$. According to Figures 15 (a) and 15(b), when the $X$-axis position is the same under different coupling states. Additionally, when $Y<1500 \mathrm{~mm}$, the bearing capacity of integral face guard is greater than that of the split face guard. When $Y>1500 \mathrm{~mm}$, the bearing capacity of the integral face guard is slightly lower than that of the split face guard, whereas both of them have poor bearing capacities. Meanwhile, the load-bearing range of the integral face guard is obviously better than that of the split face guard. According to Figures 15(c) and 15(d), the bearing capacity of the integral face guard is better than that of the split face guard under the two coupling states of $Y=840 \mathrm{~mm}$ and $Y=1300 \mathrm{~mm}$. Furthermore, it is symmetrical on both sides of $X=0 \mathrm{~mm}$. Based upon the analysis, it can be concluded that, in different coupling states, the integral face guard has a better bearing range and bearing capacity than the split face guard. 


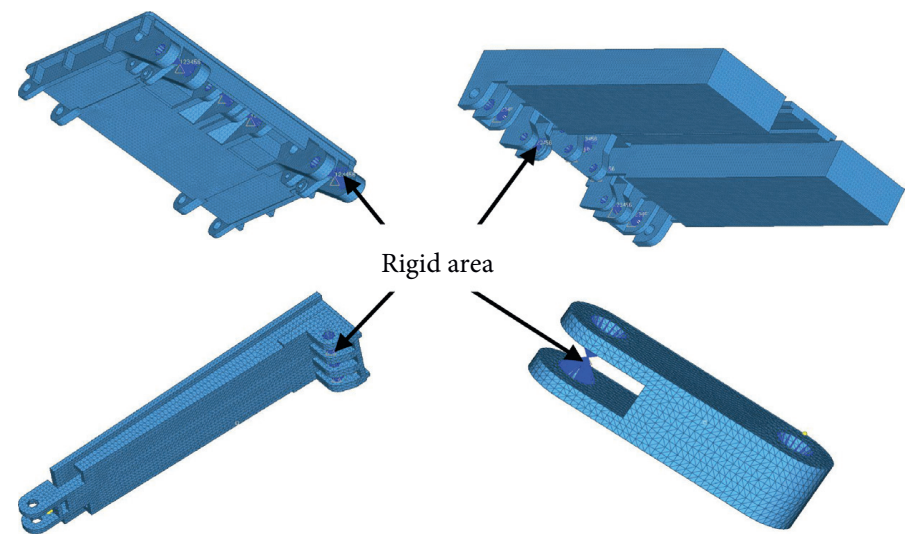

(8)

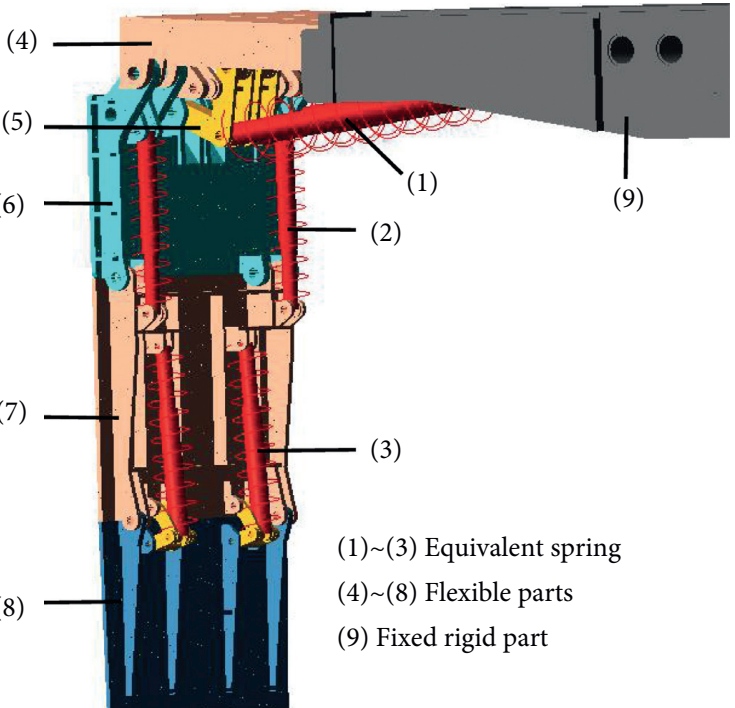

(b)

(a)

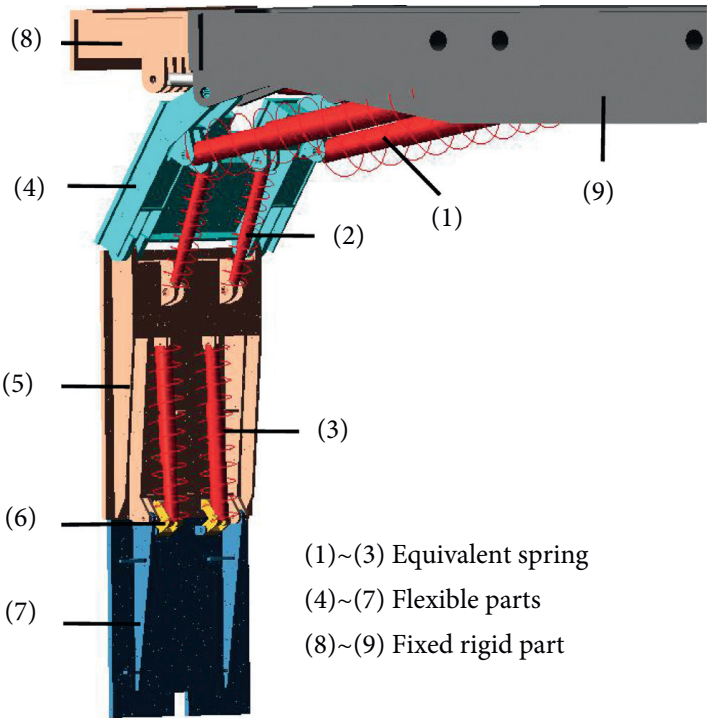

(c)

Figure 11: Numerical analysis model. (a) Rigid hinge point. (b) Numerical model of the integral face guard. (c) Numerical model of the split face guard.

4.2. Analysis of the Force Transfer Characteristics of the Hinge Point of the Face Guard Mechanism under Different Coupling States. In order to study the load-bearing characteristics of the two kinds of face guards under different coupling states with the coal wall, the numerical simulation model is used for further analysis. The load is applied to the face guard, and the stress at the hinge point between the primary face guard and the canopy or extensible canopy is taken as the research object. Because the face guard mechanism is symmetrical, only the hinge point in the positive direction of $X$-axis is analyzed in this study. The other side is the same as the case considered here. After a comprehensive analysis of the ultimate bearing capacity of the integral and split-type face guards, the minimum bearing capacity of the two kinds of face guards is $47 \mathrm{kN}$ under various coupling states. Therefore, in the analysis of bearing characteristics, to ensure that the face guard jack does not overflow, the value of applied load should be less than the minimum bearing capacity of $47 \mathrm{kN}$ within the effective working range. Meanwhile, it needs to satisfy the uniqueness of variables. Therefore, in the subsequent analysis, the load applied by coal wall to the two kinds of face guards is $45 \mathrm{kN}$.

The load-bearing characteristics of the hinged joint of face guards' results are shown in Figure 16. With the increase of $X$-axis coordinate, the stress on the hinge joint of integral and split face guards' increases. The $Y$-axis coordinate value is directly proportional to the bearing capacity at the hinge joint of the face guard. Among them, the maximum stress at the hinge joint of the integral face guard is $171 \mathrm{kN}$. Furthermore, the maximum stress at the hinge joint of the split face guard is $216 \mathrm{kN}$. Therefore, it can be inferred that the load-bearing characteristics at the hinge point of the integral 


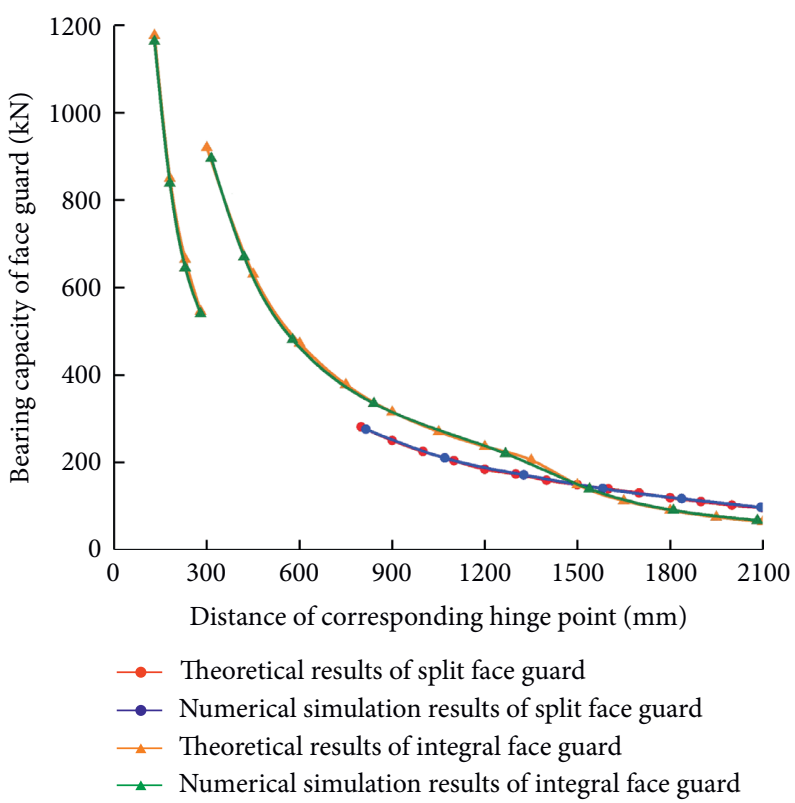

FIGURE 12: Comparative analysis of the bearing capacity of the two kinds of structural forms of face guard.

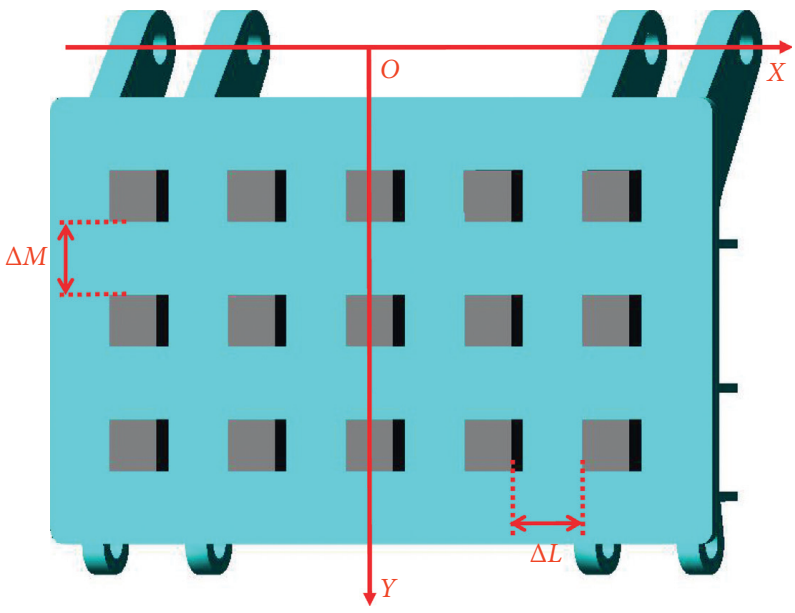

Figure 13: Schematic of the cushion block placement.

and split type face guards are affected by the coupling relationship.

Based on the above analysis, the load-bearing characteristics of the two kinds of structures in different coupling states are compared. Four rows of cushion blocks corresponding to the integral and split face guards are considered for analysis. The coordinates of the four lines are given by $X_{1}=280 \mathrm{~mm}, \quad X_{2}=560 \mathrm{~mm}, \quad Y_{1}=1800 \mathrm{~mm}, \quad$ and $Y_{2}=2100 \mathrm{~mm}$. According to Figures 17(a) and 17(b), under the coupling state of different $X$-axis coordinate values, the stress at the hinge joint of the integral face guard and the extensible canopy is less than that at the hinge point of the split face guard and the canopy. Additionally, the stress of the hinge joint of the integral face guard is about $80 \%$ of that of the split face guard. According to Figures $17(\mathrm{c})$ and $17(\mathrm{~d})$, when $X<-330 \mathrm{~mm}$, the stress of hinge joint of integral face guard is greater than that of the split face guard. It is worth noticing that the maximum difference between the two is
$13 \mathrm{kN}$. However, after $X>-330 \mathrm{~mm}$, the stress of the hinge joint of the integral face guard becomes less than that of the split face guard. In this case, the maximum difference between the two turns out to be $44 \mathrm{kN}$. Therefore, compared with the integral face guard, the pin bearing condition at the hinge joint of the split face guard is worse, indicating more wear and even failure.

According to the structural form of integral face guard, the primary face guard is connected with the extensible canopy through the four-bar linkage mechanism, as shown in Figure 2(a). The connecting rod that is hinged with the primary face guard is called the connecting $\operatorname{rod} A$. Similarly, the connecting rod that is hinged with the extensible canopy is called the connecting $\operatorname{rod} B$. The four-bar linkage is of great significance to the load-bearing characteristics of the integral face guard mechanism.

In order to study the load-bearing characteristics of the four-bar linkage, the load-bearing characteristics of the four- 


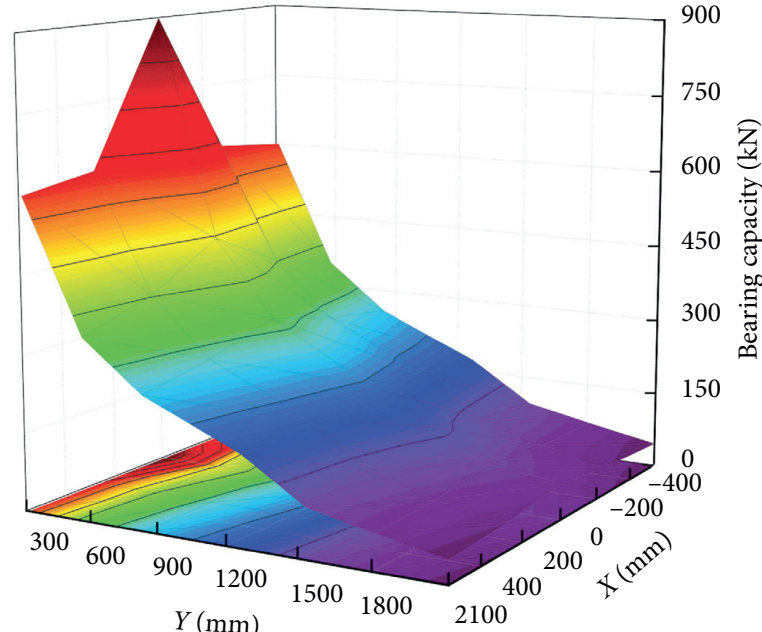

(a)

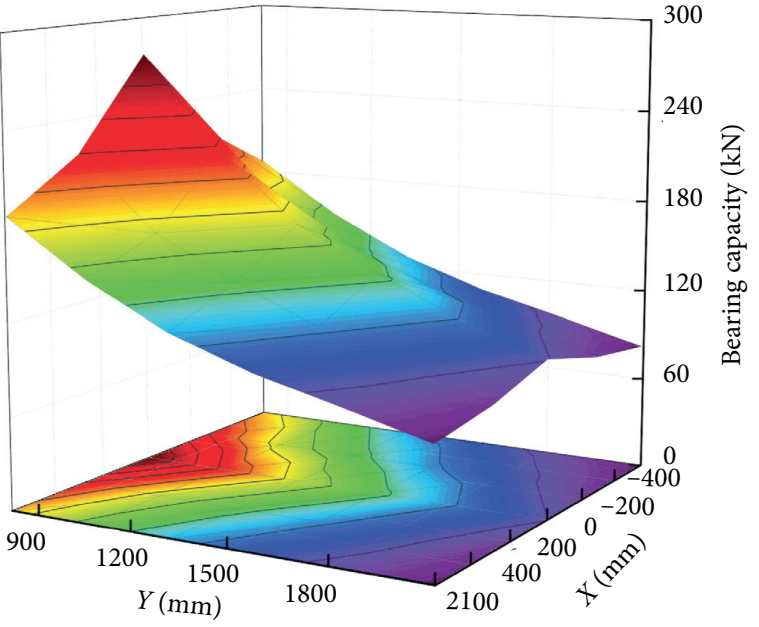

(b)

Figure 14: Curved surfaces of the bearing capacity of the face guard. (a) Bearing capacity curved surface of the integral face guard. (b) Bearing capacity curved surface of the split face guard.

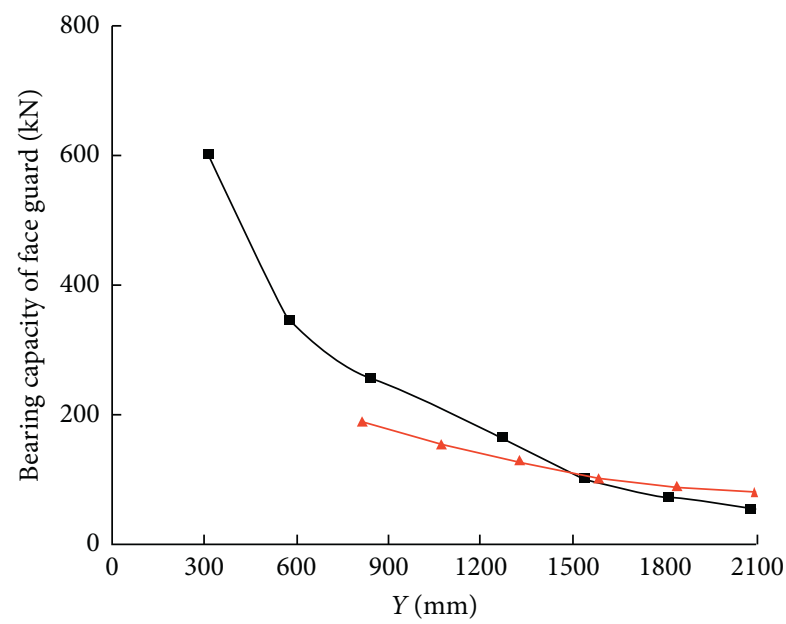

$\rightarrow \quad$ Integral face guard

$\rightarrow$ Split face guard

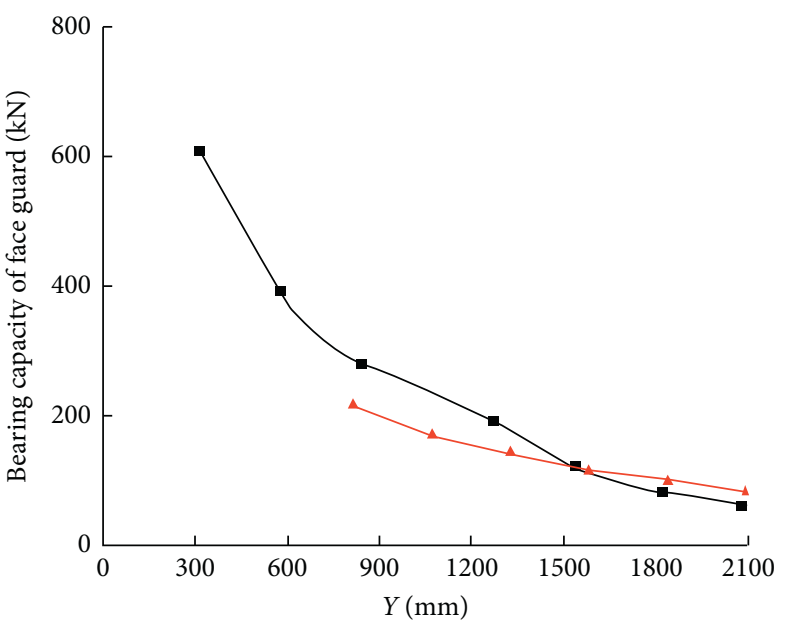

$\rightarrow$ Integral face guard

$\simeq$ Split face guard

(a)

(b)

Figure 15: Continued. 


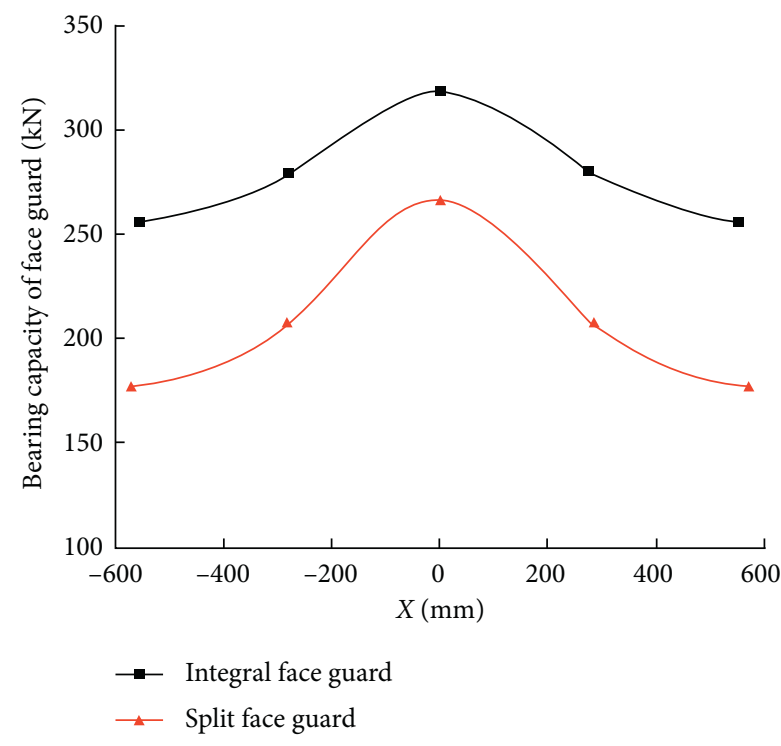

(c)

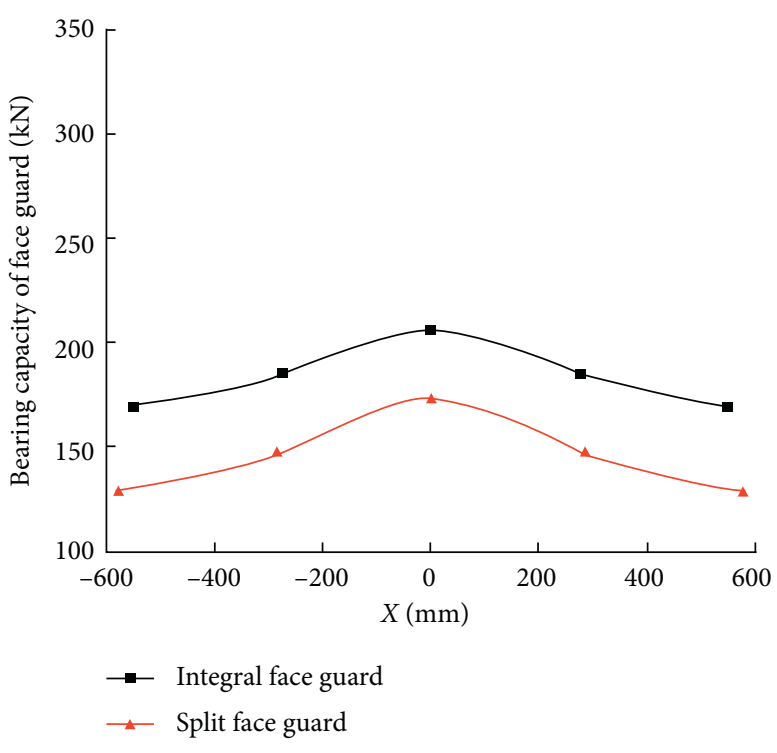

(d)

Figure 15: Comparison of the bearing capacities of different positions of face guard. (a) Coordinate value of $X$-axis is $280 \mathrm{~mm}$. (b) Coordinate value of $X$-axis is $560 \mathrm{~mm}$. (c) Coordinate value of $Y$-axis is $840 \mathrm{~mm}$. (d) Coordinate value of $Y$-axis is $1300 \mathrm{~mm}$.

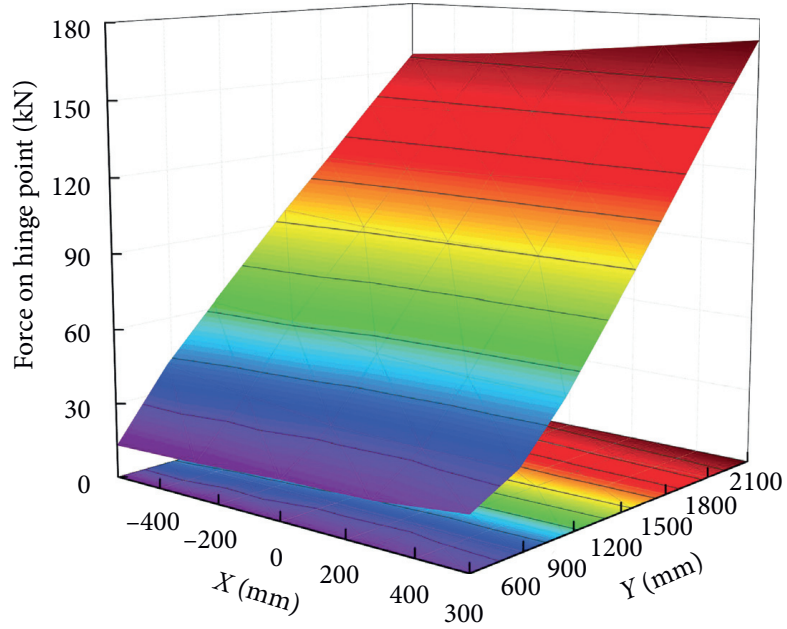

(a)

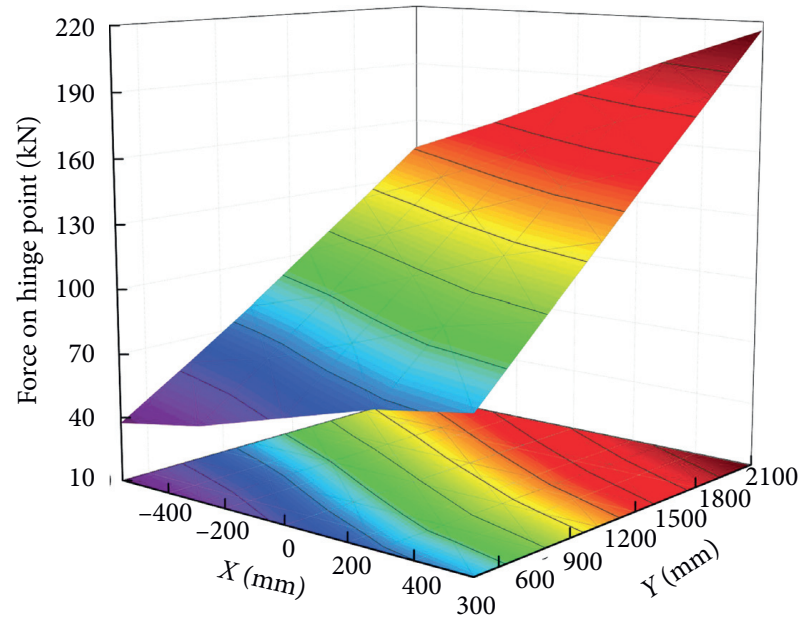

(b)

FiguRE 16: Load-bearing characteristics of the hinge joint of the face guard. (a) Load-bearing characteristics of the hinged joint of the integral face guard. (b) Load-bearing characteristics of the hinged joint of the split face guard.

bar hinge point in the integral face guard mechanism are analyzed using the above numerical simulation model. Similarly, under the premise of different coupling states between the face guard and the coal wall, a load of $45 \mathrm{kN}$ was applied to the face guard. Since the face guard mechanism is symmetrical on the left and right sides, only the hinge point on the positive side of $X$-axis is analyzed. The corresponding results are shown in Figure 18. The load-bearing characteristics of the hinge joint of connecting $\operatorname{rod} A$ and face guard, those of connecting $\operatorname{rod} A$ and connecting $\operatorname{rod} B$, and those of connecting $\operatorname{rod} B$ and extensible canopy (the bearing characteristics of the hinge joint of connecting $\operatorname{rod} A$ and connecting $\operatorname{rod} B$ are the same) are affected by the coupling state of the coal wall and face guard. Furthermore, the variation trend of stress is the same. When the $Y$-axis value is the same, the force at the hinge point increases with the increase of $X$-axis. When the value of $X$-axis is the same, the stress at the hinge increases with the increase of $Y$-axis.

Combining the results of Figures 16(a) and 18, it can be seen that under various coupling states of coal wall and face guard, in the integral face guard mechanism, the maximum stress of the hinge joint between the face guard and the 


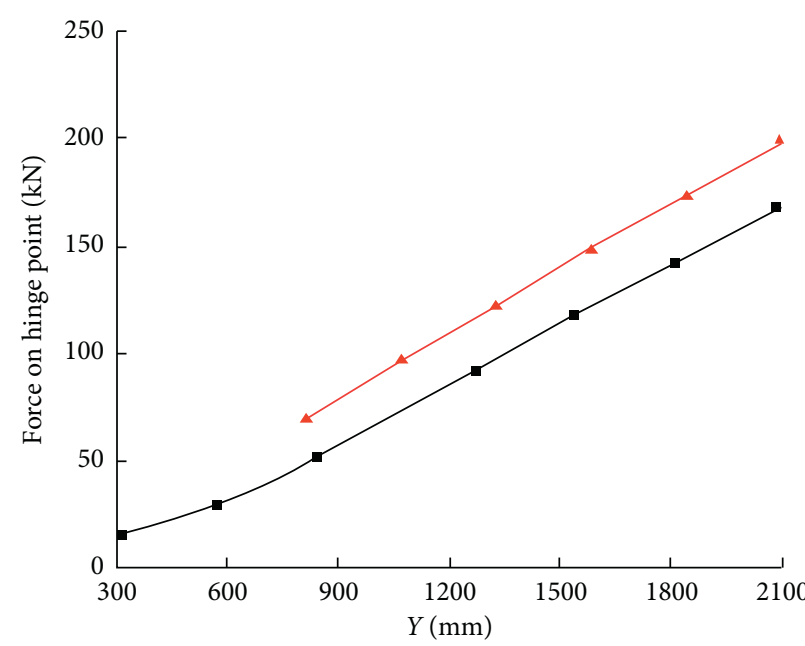

$\rightarrow \quad$ Integral face guard

$\leadsto$ Split face guard

(a)

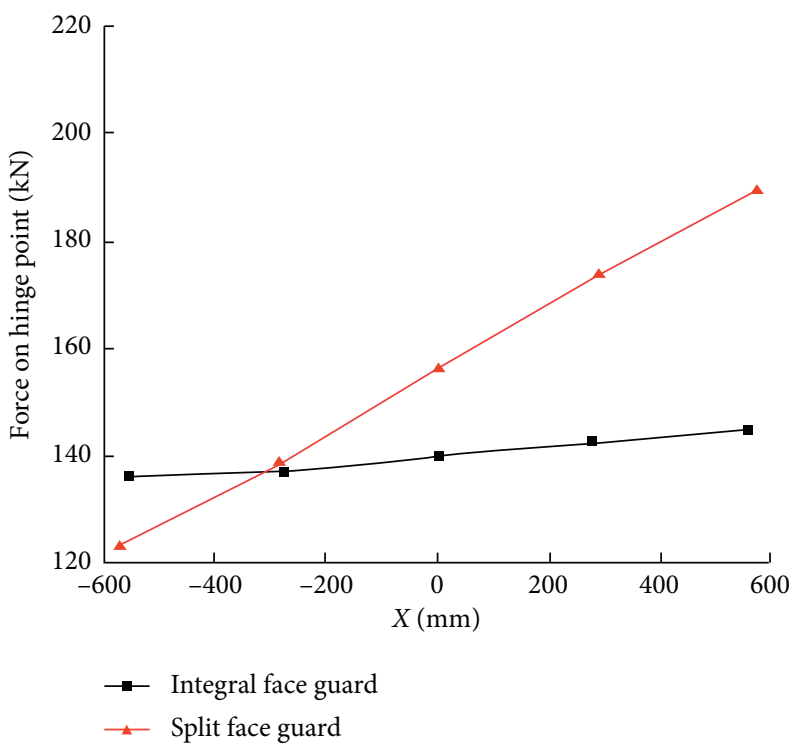

(c)

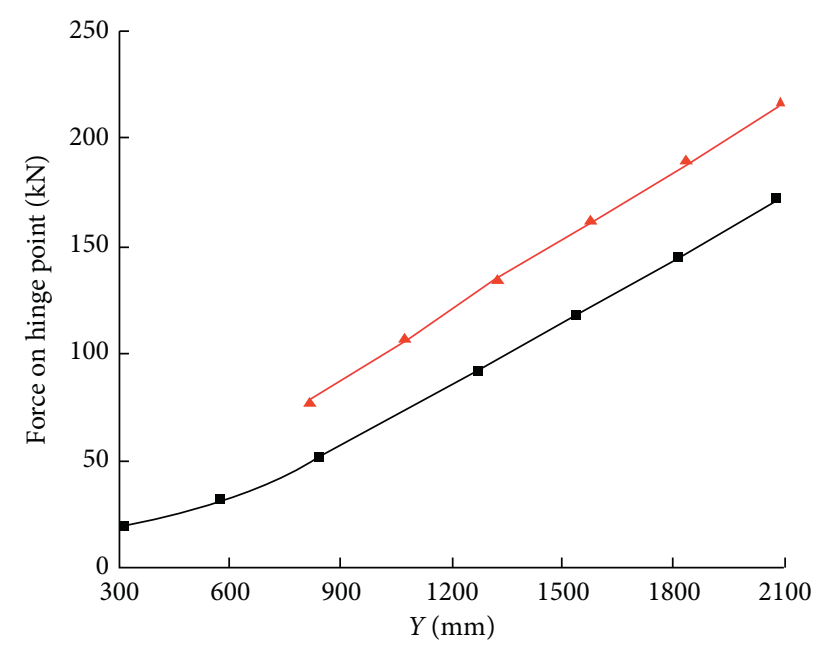

$\rightarrow \quad$ Integral face guard

$\leadsto$ Split face guard

(b)

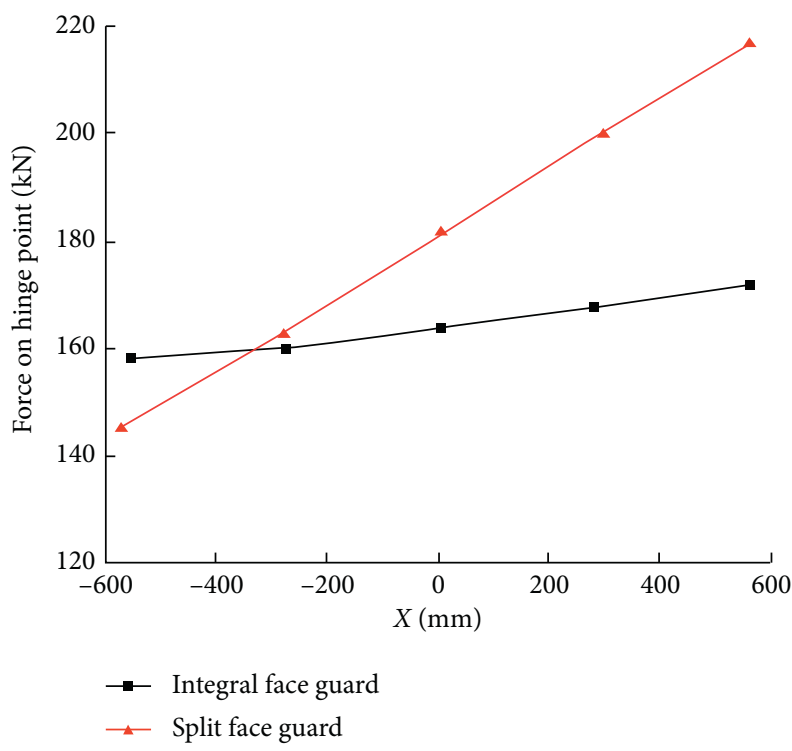

(d)

FIgURE 17: Comparison of the bearing characteristics of different positions of face guard. (a) Coordinate value of $X$-axis is $280 \mathrm{~mm}$. (b) Coordinate value of $X$-axis is $560 \mathrm{~mm}$. (c) Coordinate value of $Y$-axis is $1800 \mathrm{~mm}$. (d) Coordinate value of $Y$-axis is $2100 \mathrm{~mm}$.

extensible canopy is $171 \mathrm{kN}$. The maximum stress at the hinge point between the connecting $\operatorname{rod} A$ and the face guard is $214 \mathrm{kN}$. The maximum stress on the hinge point of the connecting $\operatorname{rod} A$ and the connecting $\operatorname{rod} B$, as well as that between the connecting $\operatorname{rod} B$ and the extensible canopy, is $119 \mathrm{kN}$. Therefore, in the process of design and material selection of the hydraulic support of the integral face guard because the pin shaft at the connecting $\operatorname{rod} A$ and the face guard has a larger limit force than the pin shaft at other hinge points during use, the bearing characteristics of the pin shaft at this position should be considered as a priority. It can avoid damage and failure in various coupling states. 


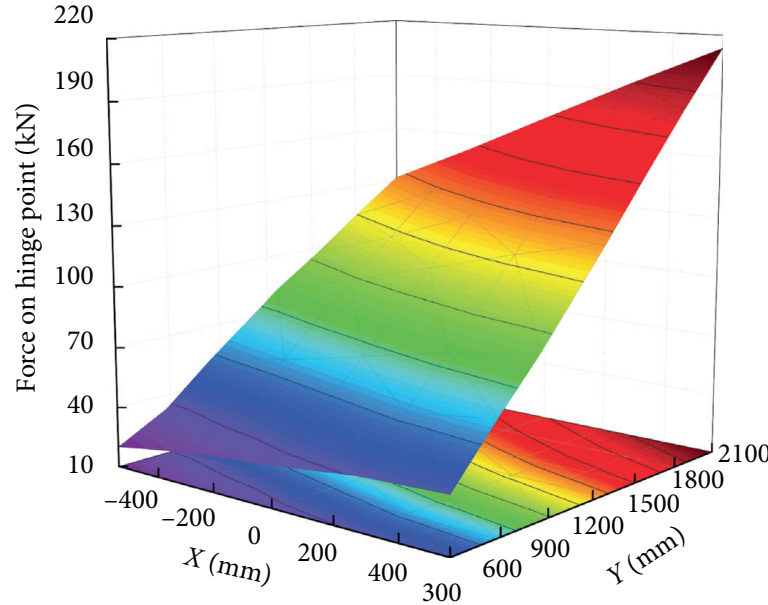

(a)

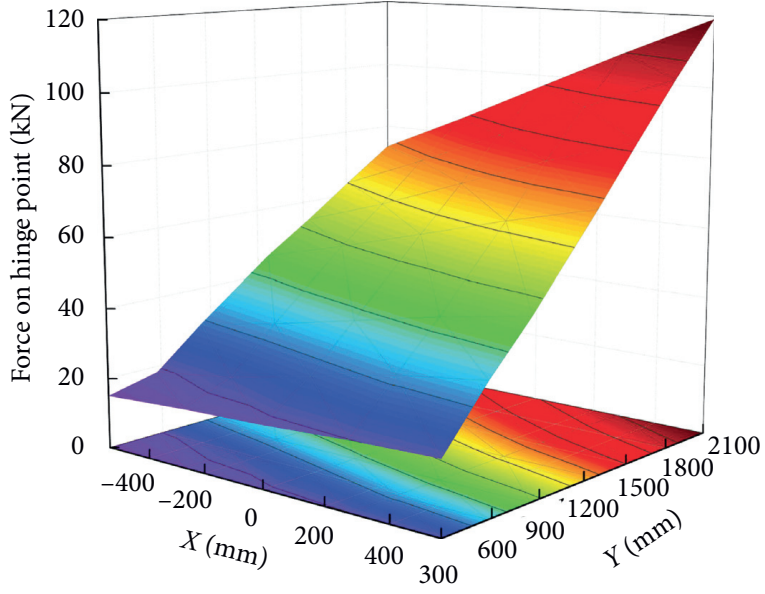

(b)

Figure 18: Load-bearing characteristics of the four-bar linkage with integral face guard. (a) Hinge joint of connecting rod $A$ and face guard. (b) Hinge joint of connecting $\operatorname{rod} A$ and connecting $\operatorname{rod} B$.

\section{Conclusions}

In this study, based upon the establishment of the theoretical model of the integral and split-type face guards and the rigid-flexible coupling numerical analysis model, the dynamic disturbance effect of the two kinds of face guards on the coal wall is analyzed. Meanwhile, the load-bearing characteristics of the two kinds of face guards under various coupling states with coal wall are analyzed and compared. Based upon the results, following conclusions are drawn.

(1) When the face guard moves closer to the coal wall, it will form a dynamic disturbance to the coal wall due to the dynamic support effect of the face guard jack. The results show that the dynamic disturbance caused by the two kinds of face guards reaches the minimum when the face guard is nearly vertical. Meanwhile, compared with the split face guard, the integral face guard has higher supporting efficiency and can reduce the exposure time of the coal wall after shearer cutting. When the dip angle of coal wall changes $\left(>10^{\circ}\right)$, the average disturbance of the split face guard to the coal wall becomes smaller.

(2) Combined with the theoretical analysis and the numerical simulation analysis, it is shown that the ultimate bearing capacity and bearing range of the integral face guard are better than those of the split face guard in various coupling states. Therefore, when other conditions, such as the face guard jack, are the same, the integral face guard can provide greater support and support range to the coal wall and can better prevent the occurrence of coal wall spalling.

(3) Based upon the numerical simulation, the two kinds of face guards are compared in different coupling states. The effect of the external load on the loadbearing characteristics of the hinge joint of the face guard is analyzed. The results show that the stress at the hinge joint of the integral face guard is significantly lower than that of the split face guard. Therefore, the structural form of the integral face guard has higher reliability. For the same material, the pin shaft is not easy to be damaged relative to the split face guard.

\section{Data Availability}

The data used to support the findings of this study are available from the corresponding author upon request.

\section{Conflicts of Interest}

The authors declare that there are no conflicts of interest.

\section{Acknowledgments}

This work was partially supported by the Key Research and Development Project of China (grant no. 2017YFC0603005), Natural Science Foundation of Shandong Province (grant nos. ZR2020QE103 and ZR2019MEE067), Horizontal Research Projects (grant no. HX2020-B48), Natural Science Foundation of China (grant nos. 51704178 and 51974170), and the Project of Shandong Province Higher Educational Young Innovative Talent Introduction and Cultivation Team (performance enhancement of deep coal mining equipment).

\section{References}

[1] G. F. Wang and Y. H. Pang, "Relationship between hydraulic support and surrounding rock coupling and its application," Journal of the China Coal Society, vol. 40, no. 1, pp. 30-34, 2015.

[2] I. F. Öge, "Prediction of top coal cavability character of a deep coal mine by empirical and numerical methods," Journal of Mining Science, vol. 54, no. 5, pp. 793-803, 2018. 
[3] A. Mangal and P. S. Paul, "Rock mechanical investigation of strata loading characteristics to assess caving and requirement of support resistance in a mechanized powered support longwall face," International Journal of Mining Science and Technology, vol. 26, no. 6, pp. 1081-1087, 2016.

[4] Y. X. Xu, G. F. Wang, M. Z. Li, J. H. Zhang, and H. J. Han, "Structure coupling between hydraulic roof support and surrounding rock in extra-thick and hard coal seam with super large cutting height and longwall top coal caving operation," Journal of the China Coal Society, vol. 44, no. 6, pp. 1666-1678, 2019.

[5] N. Hosseini, K. Goshtasbi, B. Oraee-Mirzamani, and M. Gholinejad, "Calculation of periodic roof weighting interval in longwall mining using finite element method," Arabian Journal of Geosciences, vol. 7, no. 5, pp. 1951-1956, 2014.

[6] G. S. P. Singh and U. K. Singh, "Prediction of caving behavior of strata and optimum rating of hydraulic powered support for longwall workings," International Journal of Rock Mechanics and Mining Sciences, vol. 47, no. 1, pp. 1-16, 2010.

[7] D. Szurgacz and J. Brodny, "Analysis of the influence of dynamic load on the work parameters of a powered roof support's hydraulic leg," Sustainability, vol. 11, no. 9, p. 2570, 2019.

[8] Z. H. Wang, J. C. Wang, Y. Yang, Y. S. Tang, and L. Wang, "Mechanical relation between support stiffness and longwall face stability within fully-mechanized mining faces," Journal of China University of Mining and Technology, vol. 48, no. 2, pp. 258-267, 2019.

[9] W. J. Yu and K. Li, "Deformation mechanism and control technology of surrounding rock in the deep-buried large-span chamber," Geofluids, vol. 2020, Article ID 8881319, 22 pages, 2020.

[10] W. Yu, B. Pan, F. Zhang, S. Yao, and F. Liu, "Deformation characteristics and determination of optimum supporting time of alteration rock mass in deep mine," KSCE Journal of Civil Engineering, vol. 23, no. 2, pp. 4921-4932, 2019.

[11] Q.-S. Bai, S.-H. Tu, M. Chen, and C. Zhang, "Numerical modeling of coal wall spall in a longwall face," International Journal of Rock Mechanics and Mining Sciences, vol. 88, pp. 242-253, 2016.

[12] R. C. Frith, "A holistic examination of the load rating design of longwall shields after more than half a century of mechanised longwall mining," International Journal of Mining Science and Technology, vol. 25, no. 5, pp. 687-706, 2015.

[13] B. Behera, A. Yadav, G. S. P. Singh, and S. K. Sharma, "A numerical modeling approach for evaluation of spalling associated face instability in longwall workings under massive sandstone roof," Engineering Failure Analysis, vol. 117, p. 104927, 2020.

[14] C. Zang, M. Chen, G. Zhang, K. Wang, and D. Gu, "Research on the failure process and stability control technology in a deep roadway: numerical simulation and field test," Energy Science \& Engineering, vol. 8, no. 7, pp. 2297-2310, 2020.

[15] Y. Yuan, S. H. Tu, Q. Wu, X. T. Ma, H. S. Tu, and L. L. Sun, "Mechanics of rib spalling of high coal walls under fullymechanized mining," Mining Science and Technology, vol. 21, no. 1, pp. 129-133, 2011.

[16] Y. Yuan, S. H. Tu, X. G. Zhang, and A. X. Liu, "Mechanism and control technique of rib spalling disaster in fullymechanized mining with large mining height in soft coal seam face," Disaster Advances, vol. 6, pp. 92-98, 2013.

[17] Q. Yao, X. Li, B. Sun et al., "Numerical investigation of the effects of coal seam dip angle on coal wall stability,"
International Journal of Rock Mechanics and Mining Sciences, vol. 100, pp. 298-309, 2017.

[18] C.-Y. Liu, B.-X. Huang, and F.-F. Wu, "Technical parameters of drawing and coal-gangue field movements of a fully mechanized large mining height top coal caving working face," Mining Science and Technology (China), vol. 19, no. 5, pp. 549-555, 2009.

[19] W. B. Guo, C. Y. Liu, G. W. Dong, and W. Y. Lv, "Analytical study to estimate rib spalling extent and support requirements in thick seam mining," Arabian Journal of Geosciences, vol. 12, no. 8, p. 11, 2019.

[20] Y. H. Pang and G. F. Wang, "Hydraulic support with large mining height structural optimal design and adaptability analysis," Journal of the China Coal Society, vol. 42, no. 10, pp. 2518-2527, 2017.

[21] Y. H. Pang, G. F. Wang, and Q. L. Yao, "Double-factor control method for calculating hydraulic support working resistance for longwall mining with large mining height," Arabian Journal of Geosciences, vol. 13, no. 6, p. 252, 2020.

[22] B. T. Shen, Y. Duan, X. Luo et al., "Monitoring and modelling stress state near major geological structures in an underground coal mine for coal burst assessment," International Journal of Rock Mechanics and Mining Sciences, vol. 129, p. 104294, 2020.

[23] C. Li, T. H. Kang, X. P. Li, L. G. Li, X. Y. Zhang, and R. X. Zhang, "Theoretical investigation of the sliding instability and caving depth of coal wall workface based on the bishop strip method," Advances in Civil Engineering, vol. 2019, Article ID 3065930, 8 pages, 2019.

[24] B. Behera, A. Yadav, G. S. P. Singh, and S. K. Sharma, "Numerical modeling study of the geo-mechanical response of strata in longwall operations with particular reference to Indian geo-mining conditions," Rock Mechanics and Rock Engineering, vol. 53, no. 4, pp. 1827-1856, 2020.

[25] M. Witek and S. Prusek, "Numerical calculations of shield support stress based on laboratory test results," Computers and Geotechnics, vol. 72, pp. 74-88, 2016.

[26] S. Prusek, M. Płonka, and A. Walentek, "Applying the ground reaction curve concept to the assessment of shield support performance in longwall faces," Arabian Journal of Geosciences, vol. 9, no. 3, pp. 1-15, 2016.

[27] S. R. Islavath, D. Deb, and H. Kumar, "Numerical analysis of a longwall mining cycle and development of a composite longwall index," International Journal of Rock Mechanics and Mining Sciences, vol. 89, pp. 43-54, 2016.

[28] A. K. Verma and D. Deb, "Numerical analysis of an interaction between hydraulic-powered support and surrounding rock strata," International Journal of Geomechanics, vol. 13, no. 2, pp. 181-192, 2013.

[29] Y. X. Xu, G. F. Wang, M. Z. Li, Y. J. Xu, H. J. Han, and J. H. Zhang, "Investigation on coal face slabbed spalling features and reasonable control at the longwall face with super large cutting height and longwall top coal caving method," Journal of the China Coal Society, vol. 3, pp. 1-13, 2020.

[30] D. F. Malan, "Manuel rocha medal recipient simulating the time-dependent behaviour of excavations in hard rock," Rock Mechanics and Rock Engineering, vol. 35, no. 4, pp. 225-254, 2002.

[31] Z. Meng, Q. Zeng, K. Gao, S. Kong, P. Liu, and L. Wan, "Failure analysis of super-large mining height powered support," Engineering Failure Analysis, vol. 92, pp. 378-391, 2018.

[32] Y. Y. Xie, Z. S. Meng, Q. L. Zeng, C. X. Yang, and K. D. Gao, "Analysis of distribution characteristics of study on floor 
specific pressure of hydraulic support for deep mining based on impact loading," Journal of the China Coal Society, vol. 45, no. 3, pp. 982-989, 2020.

[33] Q.-L. Zeng, Z.-S. Meng, L.-R. Wan, and C.-L. Wang, “Analysis on force transmission characteristics of two-legged shield support under impact loading," Shock and Vibration, vol. 2018, Article ID 3854684, 10 pages, 2018. 